\title{
Research on Roof Fracture Characteristics of Gob-Side Entry Retaining with Roof Cutting and Non-pillar Mining in Thick Coal Seam, China
}

\author{
Mengye Zhao $\mathbb{D} \cdot$ Lei Zhu $\cdot$ Qingxiang Huang $\cdot$ Kai Xu $\cdot$ Yuyi Wu • \\ Wenzhe Gu
}

Received: 30 April 2021/ Accepted: 7 August 2021/Published online: 8 September 2021

(C) The Author(s) 2021

\begin{abstract}
Based on the S1201-2 large height mining in the 2-2 coal seam of Ningtiaota colliery with on-site microseismic measurement, physical simulation and theoretical analysis methods, this paper explores the rule of roof movement in thick coal seams with roof cutting and non-pillar (hereinafter referred to as RCNP) mining, so as to obtain scientific and effective theoretical basis for entry support and to summarize the regional structural characteristics and dynamic periodic fracture characteristics. As can be seen from microseismic events, the entry roof is featured by "two zones and one line" along the horizontal direction, namely, the crack generation area, the roof movement area. Additionally, and the obvious lateral breaking of the entry roof on the coal wall is a typical feature of the thick coal seam with RCN-P mining. The roof is vertically divided into "three zones", the crack generation area, the roof movement area and the crack development area. The roof cutting activity mainly affects the overburden activity within the basic roof height range, which is also the roof movement area. In addition, the distribution frequency and the intensity
\end{abstract}

M. Zhao $(\bowtie) \cdot$ L. Zhu $\cdot$ K. Xu · Y. Wu · W. Gu

China Coal Energy Research Institute Co., Ltd,

Xi' an 710000, Shaanxi, China

e-mail: zhaomengye@chinacoal.com

M. Zhao · Q. Huang

School of Energy Engineering, Xi'an University of

Science and Technology, Xi' an 710054,

Shaanxi, China of microseismic events indicate the roof periodic breaking characteristics. The "breaking pressure relief," "advanced crack development," and "the limit breaking state" of roof breaking corresponds to the initial, middle, and final stage of breaking in the periodic weighting process, respectively. Compared with the normal mining, the RCN-P mining reduces the periodic weighting length and increases the pressure strength. As is shown in the physical simulation experiment, the basic roof and the cutting control layer in the "regional structural characteristics" constitute the "large" and "small" structures with RCN-P mining. The basic roof key layer is the core to control the stability of the strata, and the breaking process from the cantilever beam to the short masonry beam of the roof-cutting control layer is the main cause of the entry stress. Correspondingly, the basic structure model of "short masonry-hinged" roof was proposed and the calculation method of support was established for the entry with RCN-P mining in thick coal seam, providing a research foundation for scientific and effective rock formation control.

Keywords Roof cutting and non-pillar (RCN-P) mining $\cdot$ Roof movement $\cdot$ Microseismic monitoring · Roof cutting control layer - Short masonry beammasonry beam 


\section{Introduction}

Gob-side entry retaining with RCN-P mining is an efficient and green coal mining technology (He et al. 2017a, 2011). With only one or without the entry needs to be excavated at a working face to achieve complete recovery of coal pillars (Zhen et al. 2019; Liu 1994). Non-pillar mining sets off the protective effect of the section coal pillars, which leads to the stability of the surrounding rock closely related to the breaking of the roof movement (Yang et al. 2019; Mahdevari et al. 2017). Due to the lack of support on one side of the pillar, the basic surrounding rock structure (Huang and Zheng 2016; Huang et al. 2016) composition of the entry has changed (Song et al. 2010), as a result, the roof movement law cannot be applied in accordance with the tradition (Qian 2015; Qian et al. 2018).

Manchao He proposed an innovative coal nonpillar longwall mining method (Li et al. 2015; He et al. 2017b). The mechanical model is established and the mechanism of the new method is discussed. A directional roof fracturing technique to promote roof caving in goaf is proposed. Constant resistance and large deformation anchor cable (CRLDA) are used to stabilize roof of entry. Field monitoring shows that the reserved items are stable, which meets the actual needs of field mining (Zhu et al. 2019). Jinzhu Hu et al. established the mechanical model of roof cutting of GERRC, and pointed out that the depth and angle of roof cutting were the key parameters, and analyzed the reinforced concrete at different depths and angles ( $\mathrm{Hu}$ et al. 2019). Xiao Liu et al. analyzed the stress characteristics of the goaf, and introduced the equivalent concentrated load in entry. The mechanical model of roof cutting support is established, and the applicable scope and key parameters of determination method are analysed (Liu et al. 2020; Hua and Zhang 2009). Nong Zhang et al. analyzed the stability of goaf retaining entry along goaf in four stopes in China and evaluated the influencing factors of entry deformation, such as mining depth, support strength, and mining depth. On the basis of continuous superposition, the supporting resistance model of the side wall of the filling goaf is derived (Zhang et al. 2012; Nong et al. 2014). Lifeng Li et al. verified the model parameters through the measured leading abutment pressure and numerical calculation, and studied the energy density in the mining process. The failure of the lateral abutment energy supports body of the adjacent working face, and the large deformation of surrounding rock often occurs in goaf side entry under the influence of multiple energy disturbances ( $\mathrm{Li}$ et al. 2019; Luan et al. 2018).

However, the selection of on-site support mostly relies on on-site experience and lacks the corresponding theoretical basis, especially the related research on roof failure characteristics. Therefore, based on the research traditional roof structure and overburden movement (Huang 2002; Huang et al. 2019), by means of microseismic monitoring(Ma et al. 2021; Mikkelsen and Green 2003; Guo 2020; Wang et al. 2020), the breaking process of entry with RCN-P is monitored on site to clarify its breaking process and structural form. Being both theoretically and practically significant, the research results can provide references for the mechanism of entry failure, the relationship between "support and surrounding rock", the selection of support equipment, the design of entry retention parameters and the optimization of entry retention process.

\section{Engineering Background}

\subsection{Overview of the Research Area}

The colliery of Ningtiaota is one of the three pairs of super large mines invested and constructed by Shaanxi Coal chemical Industry Group Company in the south of Shenfu mining area. The mine design production capacity is $12.00 \mathrm{MT} / \mathrm{a}$, and the approved production capacity is $18.00 \mathrm{MT} / \mathrm{a}$. Ningtiaota colliery is the first mine in China that realized the technology of nonpillar and roof cutting mining with large mining height(Wang et al. 2017). For a better study of the characteristics of roof breakage under non-pillar roof cutting, on-site microseismic monitoring was carried out on the mining face of S1201-2 Ningtiaota colliery.

The mining face of S1201-2 is located in the south No.1 panel. The mining face is reserved for S1201-3 in the west and S1201-1 mined in the east. The mining face layout is shown in Fig. 1. The main mining face is $2^{-2}$ coal seam, based on the data in the study area and surrounding boreholes, the average thickness of $2^{-2}$ coal seam is $4.33 \mathrm{~m}$. 


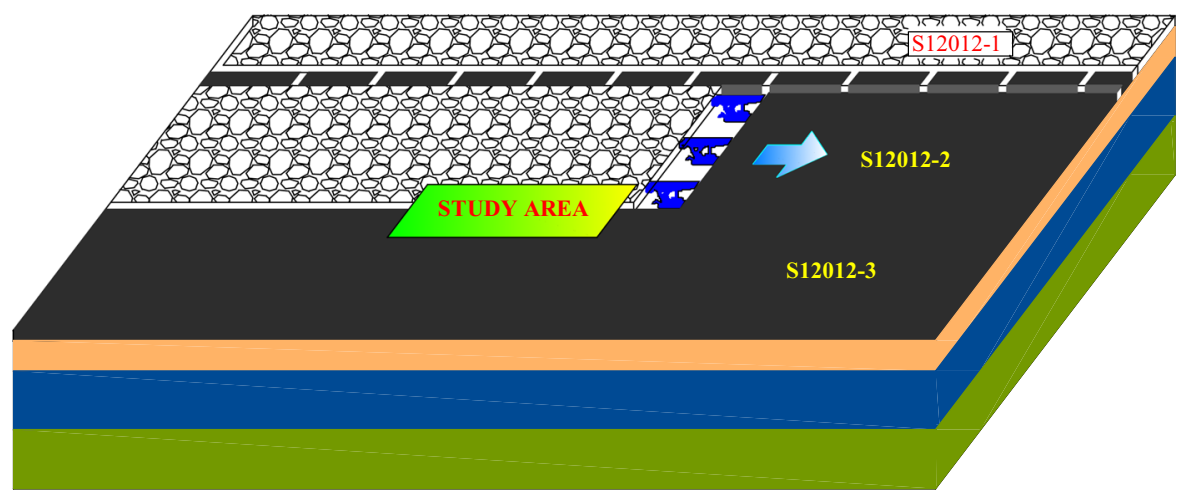

Fig. 1 Study area layout

\subsection{Entry Support}

In the process of RCN-P mining, the entry goes through multiple stages, such as primary mining, primary mining stability and secondary mining. The surrounding rock deformation of the entry is considerable and long lasting. "Anchor cable + plastic steel mesh " is used to support the roof on site. The coal side adopts the support of "fiberglass bolt + lead wire mesh". The gravel side is supported by "wavy bolt + steel mesh", as shown in Fig. 2 .

(1) Surrounding rock supporting
Five anchor cables are arranged in each $800 \mathrm{~mm}$ spacing row of the remaining entry. Length: $10.5 \mathrm{~m}$, diameter: $21.8 \mathrm{~mm}$. The pre-tightening force is $28 \mathrm{~T}$, and a W steel strip with a length of $2.0 \mathrm{~m}$ is used to connect every 3 anchor cables along the entry with constant resistance. Arranged variously, the coal side adopts the support of "fiberglass bolt $+8 \#$ lead wire mesh ". The length of the bolt is $1.6 \mathrm{~m}$ and the diameter of the bolt is $18 \mathrm{~mm}$.

(2) Temporary reinforcement of roof support During the advancing process of the mining face, a certain range behind the mining face is the main area
Fig. 2 Layout of entry section

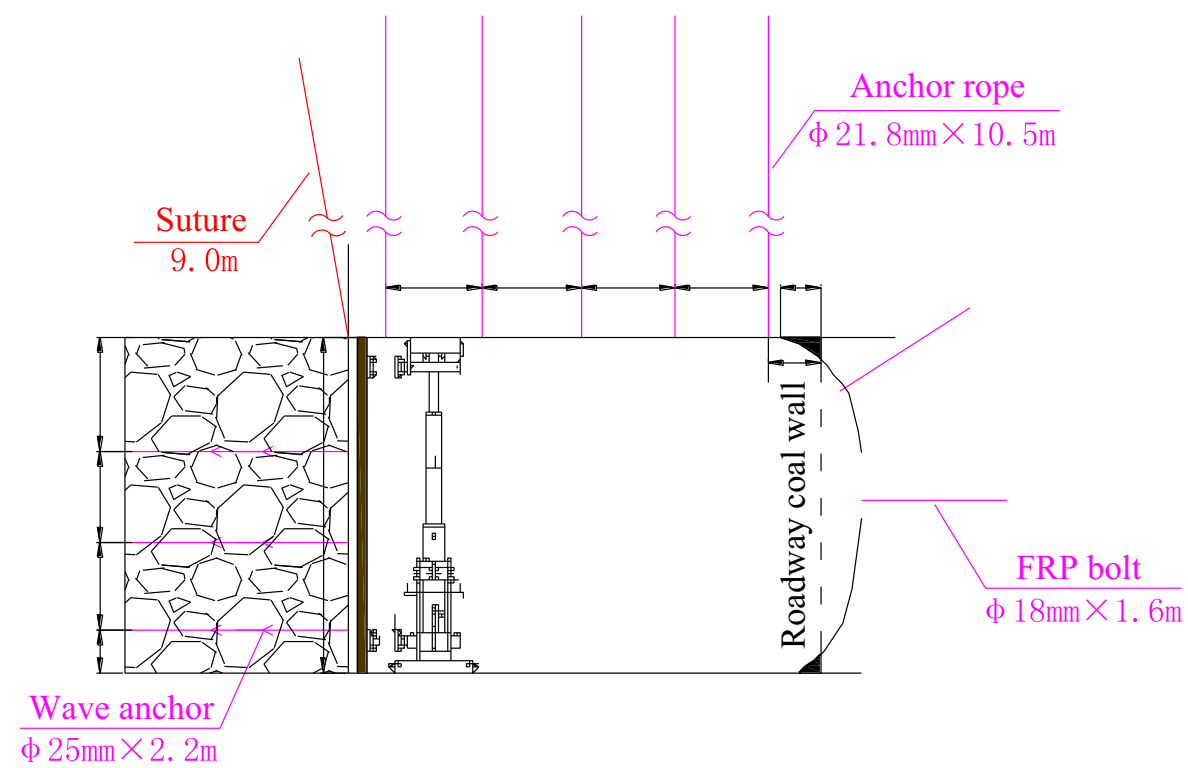


where the roof moves, resulting in severe deformation of the surrounding rock of the entry, which requires key control. According to the law of appearance of mine pressure on site, the unit support is used to temporarily strengthen the support behind the mining face.

(3) Caved gangue support

The control effect of gangue caving in the goaf determines the effect of entry retention. The roof rock gradually collapses as the mining face is mined. Method of unit support + U-shaped steel + metal mesh is adopted in order to prevent the crushed rock slab from bulging into the lane when it is not compacted and instable, and to enhance the stability of the collapsed gangue and improve the control effect on the roof structure.

\section{Analysis of Microseismic Field Measurement of Roof Movement}

\subsection{Monitoring System Establishment}

This study explores the roof movement process by means of microseismic monitoring. Microseismic monitoring monitors the generation, expansion, and internal energy accumulation of cracks in the rock during the friction. It propagates in the form of $\mathrm{P}$ and $\mathrm{S}$ waves and accurately determines the time, location, and magnitude of the microseismic event in the rock mass (real-time air strength), so as to make a qualitative and quantitative evaluation of the activity range, stability and development trend of the rock mass damage.

\section{(1) Measuring point layout}

The S1201-2 mining face of Ningtiaota colliery adopts the mining method of RCN-P, so that the entry is retained to serve the S1201-3 mining face. The exploration area is located in the belt along the groove near the stop line, and a group of microseismic sensors are arranged at every $30 \mathrm{~m}$. The sensor is arranged in the roof stable rock formation in a manner that follows the mining. On-site detection is based on the positioning principle and the sensor is designed to be vertically arranged on three layers, the sensor layout is shown in Figs. 3 and 4, the drilling construction is

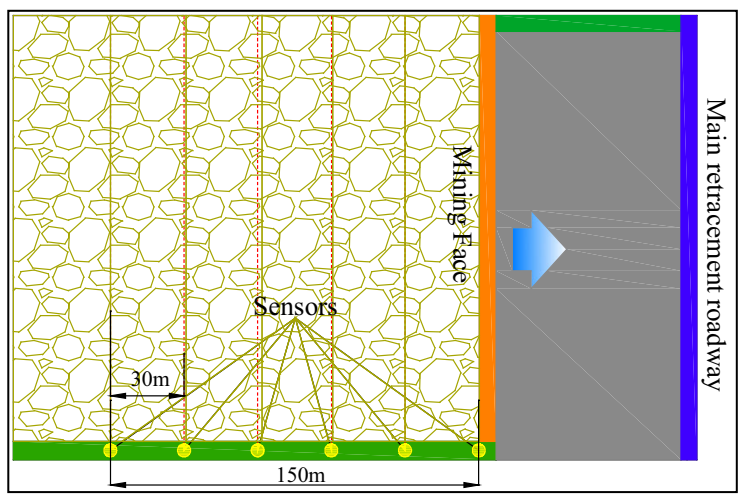

Fig. 3 Top view of microseismic sensor measuring point layout

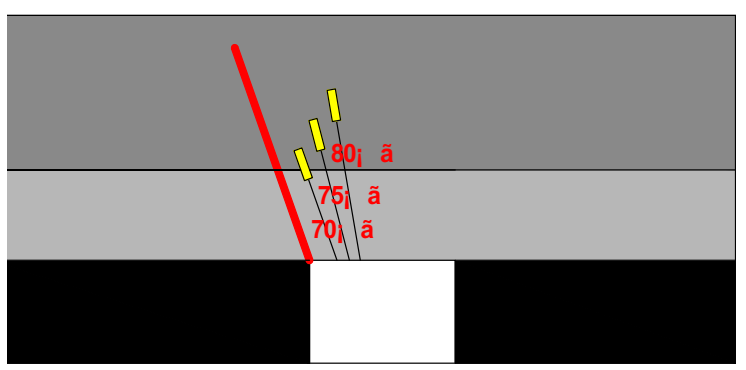

Fig. 4 Side view of microseismic sensor layout

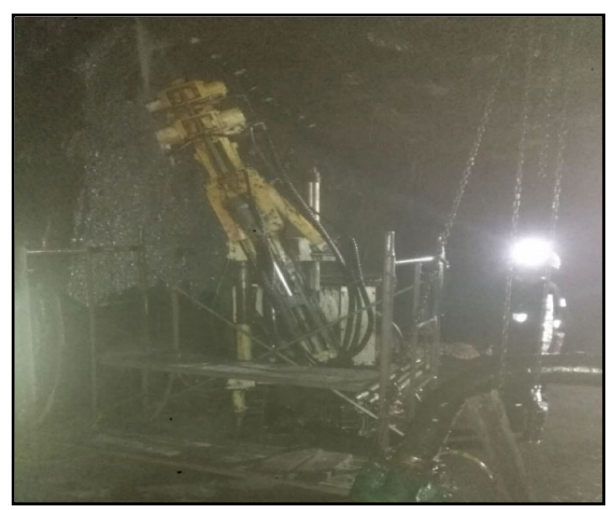

Fig. 5 Drilling installation construction

shown in Fig. 5, and the parameters are shown in Table 1.

(2) Monitoring process

The microseismic monitoring system mainly includes: sensors, paladin digital signal acquisition system, ground host processing system, transceivers, cables, optical cables, and junction boxes. The ground host is 
Table 1 Drilling parameter design

\begin{tabular}{lllllll}
\hline Number & $\begin{array}{l}\text { Design depth } \\
(\mathrm{m})\end{array}$ & $\begin{array}{l}\text { Measured depth } \\
(\mathrm{m})\end{array}$ & $\begin{array}{l}\text { Design } \\
\text { inclination }\left(^{\circ}\right)\end{array}$ & $\begin{array}{l}\text { Measured } \\
\text { inclination }\left({ }^{\circ}\right)\end{array}$ & $\begin{array}{l}\text { Design aperture } \\
(\mathrm{mm})\end{array}$ & $\begin{array}{l}\text { Measured aperture } \\
(\mathrm{mm})\end{array}$ \\
\hline $1 \#$ & 5 & 4.97 & 70 & 69.8 & 50 & 49.5 \\
$2 \#$ & 7 & 6.96 & 80 & 79.1 & 50 & 48.7 \\
$3 \#$ & 6 & 5.88 & 75 & 75.8 & 50 & 48.7 \\
$4 \#$ & 5 & 4.96 & 70 & 68.7 & 50 & 48.6 \\
$5 \#$ & 7 & 6.97 & 80 & 79.8 & 50 & 47.9 \\
$6 \#$ & 6 & 5.95 & 75 & 75.4 & 50 & 49.4 \\
\hline
\end{tabular}

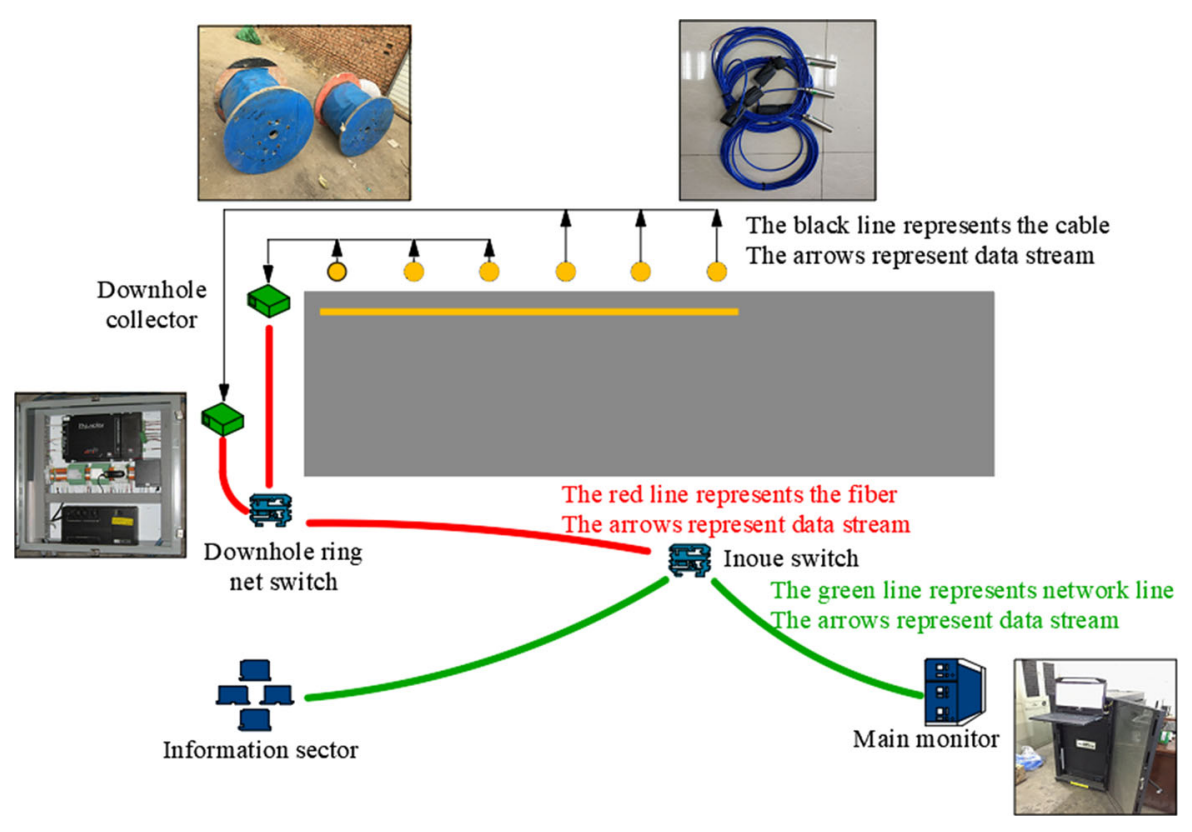

Fig. 6 Communication line layout

placed in the wellhead fleet office, and the digital signal acquisition system is transported to the S1201-2 retracement window (Fig. 6) by a rubber wheeled vehicle.

\section{(3) Run test}

$1 \quad$ Host and sensor parameter setting

System and sensor parameter setting are the main task of ESG system debugging.

2 Establishment of microseismic waveform database and filtering processing
Underground noise varies widely. Even the same kind of noises have different characteristics because of different conditions and environmental factors. It is necessary, therefore, to deal with all kinds of underground noises. Only by performing full waveform analysis can their characteristics and changes be accurately grasped.

During the test, each type of noise was repeatedly analyzed, summarized and classified, and a database of underground noise signals and AE acoustic emissions suitable for Caragana mine were established (as shown in Table 2). Among them: the X-axis in all the following waveform diagrams signifies time (ms), and the $\mathrm{Y}$-axis refers to the amplitude value, that is, the output voltage (v). 
Table 2 Typical waveform signal

\begin{tabular}{|c|c|c|c|}
\hline $\begin{array}{l}\text { The name of } \\
\text { the noise }\end{array}$ & Waveform figure & $\begin{array}{l}\text { The name of } \\
\text { the noise }\end{array}$ & Waveform figure \\
\hline $\begin{array}{l}\text { Standard } \\
\text { microseismic } \\
\text { waveform }\end{array}$ & 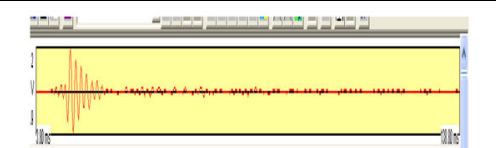 & $\begin{array}{l}\text { Coal cutter } \\
\text { Operation }\end{array}$ & 4 \\
\hline $\begin{array}{l}\text { Undergroun } \\
\mathrm{d} \text { operation } \\
\text { vehicle } \\
\text { passing }\end{array}$ & 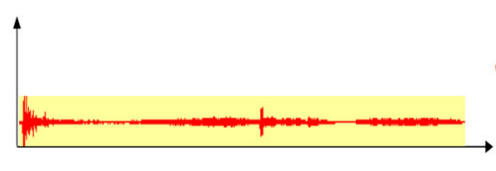 & $\begin{array}{l}\text { Rubber wheel } \\
\text { truck loading, } \\
\text { unloading }\end{array}$ & $\longrightarrow+\ldots$ \\
\hline $\begin{array}{l}\text { Blasting of } \\
\text { roof cutting }\end{array}$ & $+\quad+$ & $\begin{array}{l}\text { Water flow hits } \\
\text { rock mass of } \\
\text { entry }\end{array}$ & 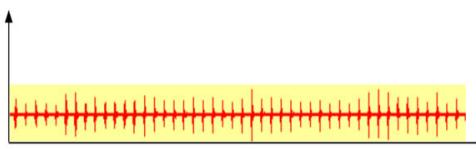 \\
\hline $\begin{array}{l}\text { Effective AE } \\
\text { signal after } \\
\text { roof cutting }\end{array}$ & 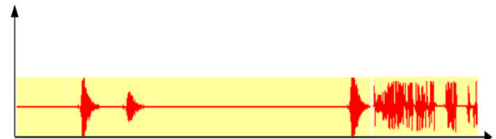 & $\begin{array}{l}\text { Metallic } \\
\text { impingement } \\
\text { rock }\end{array}$ & $1+1,11,1,1,1$ \\
\hline
\end{tabular}

It can be seen from the above listed waveform diagrams that the characteristics of various signal waveforms caused by different reasons, and most of the waveforms have a short duration, ranging from tens to thousands of milliseconds.

The signal duration is the shortest when hitting metal objects, such as bolts inside the rock mass and the surrounding rock of the entry, generally about $10 \mathrm{~ms}$;

The passing signal of the minecart is a long interference signal, generally as long as about $1 \mathrm{~min}$, which can be clearly distinguished;

The vibration caused by the rotation of the fan does not have much regularity with the loading and unloading signal of the mine car, and the amplitude is not the same;

The regularity of the impact of the water flow from the roof drain hole on the entry rock mass is obvious;

The signals generated by roof cutting energy blasting and percussion on the surrounding rock mass of the entry are generally regular, and the amplitude of each vibration waveform is roughly the same. In addition, the duration is very short, and the coda is not fully developed;

The above list is only the typical waveform signals monitored since the operation of the system. With the continuous improvement of monitoring data, the types of waveform signals obtained will be complete. Comparison of the characteristics of various signals.

The entire preparation, installation, commissioning, monitoring and analysis work spanned over one year from May 2018 to May 2019. The specific monitoring work completed is shown in Table 3.

\subsection{Analysis of Characteristics of Microseismic Events During Roof Failure}

(1) Distribution characteristics of microseismic events

From December 13, 2018 to January 10, 2019, continuous on-site monitoring of microseismic events with an elevation of $1285 \mathrm{~m}$ and a strike length of $180 \mathrm{~m}$ was performed on the S1201-2 mining face of Ningtiaota colliery. During the microseismic monitoring period, 2875 monitoring data were collected. The distribution of microseismic events is shown in Figure 7. The sphere in the figure represents the microrupture of the overburden of the mining face. The shape of the event indicates the energy of the event. The larger the shape of the event, the greater the 
Table 3 Experimental parameter ratio

\begin{tabular}{|c|c|c|c|c|c|c|c|c|}
\hline Number & Name of rock & $\begin{array}{l}\text { Rock } \\
\text { thickness/m }\end{array}$ & $\begin{array}{l}\text { Thickness of experimental } \\
\text { model/cm }\end{array}$ & $\begin{array}{l}\text { The ratio of } \\
\text { material }\end{array}$ & $\begin{array}{l}\text { River } \\
\text { sand }\end{array}$ & $\begin{array}{l}\text { Material/ } \\
\text { kg } \\
\text { Gypsum }\end{array}$ & $\begin{array}{l}\text { Putty } \\
\text { powder }\end{array}$ & $\begin{array}{l}\text { Coal } \\
\text { ash }\end{array}$ \\
\hline 1 & Post stone & 9.21 & 18 & 719 & 11.34 & 0.16 & 1.46 & \\
\hline 2 & $\begin{array}{l}\text { Medium } \\
\text { sandstone }\end{array}$ & 4.6 & 9 & 737 & 11.34 & 0.48 & 1.14 & \\
\hline 3 & $\begin{array}{l}\text { Sand } \\
\text { mudstone }\end{array}$ & 3.1 & 6 & 846 & 11.52 & 0.57 & 0.87 & \\
\hline 4 & Siltstone & 7.86 & 15 & 719 & 11.34 & 0.16 & 1.46 & \\
\hline 5 & $\begin{array}{l}\text { Carbon } \\
\text { mudstone }\end{array}$ & 0.4 & 1 & 928 & 4.32 & 0.1 & 0.38 & \\
\hline 6 & $\begin{array}{l}\text { Sandy } \\
\text { mudstone }\end{array}$ & 1.23 & 2.6 & 846 & 9.99 & 0.49 & 0.75 & \\
\hline 7 & $\begin{array}{l}\text { No. } 5 \text { coal } \\
\text { seam }\end{array}$ & 3.25 & 6.4 & 20:1:5:20 & 9.8 & 0.24 & 1.2 & 3.25 \\
\hline 8 & Siltstone & 5.15 & 4.5 & 719 & 11.34 & 0.16 & 1.46 & \\
\hline
\end{tabular}

energy. The change in color indicates the magnitude of the moment magnitude. With the color changing from purple to yellow, the moment magnitude gradually increases.

The statistical results are shown in Table 4 .

(2) Horizontal distribution characteristics of microseismic events

The horizontal distribution characteristics of microseismic events were analyzed (Figure 8) during mining. The farthest end of the microseismic event concentrated area of the leading face was between 15 and $24 \mathrm{~m}$ from the mining face, the concentrated lagging mining face of which was at the mining face. Microseismic events were always concentrated within the range of $31-45 \mathrm{~m}$ behind the mining face, and the roof overlying rock movement is relatively active.

Statistics and analysis of the microseismic events (2875 in total) in the microseismic area affected by the motion were carried out, and the cumulative energy value of the microseismic events was suppressed according to the period that was taken as the threshold value to judge whether the rock formation has been damaged to the fracture. The maximum accumulated energy of microseismic events in different areas of the leading mining face exceed the threshold $1.4 \mathrm{E}+05$ Joule. The mining face corresponding to the mining face was mined. The cracks in this area were derived from a large number of microfractures into macro cracks. According to the microseismic statistical results (as shown in Fig. 9), within the range of $10-15 \mathrm{~m}$ from the advanced mining face, the roof gradually formed a macroscopic fracture, which conformed to the basic law of advanced fracture of the roof.

Taking the microseismic event from the mining face to $30 \mathrm{~m}$ (Fig. 7c) as an example, the analysis shows that the horizontal distribution of the microseismic event has obvious regional characteristics. According to the energy and density of the microseismic event, the groutable roof is divided into the crack generation area and the roof movement area. In addition, the lateral breaking position of the roof can be determined along the inclination direction.

\section{Crack Generation area}

15-25 $\mathrm{m}$ ahead of the mining face is the generation area of roof cracks. The density and energy of microseismic events in the area are generally low. The roof is dominated by the generation and development of microcracks. The distribution of microseismic events presents asymmetrical characteristics. The position of the entry gradually decreases to the middle of the mining face.

The mining face is $10-15 \mathrm{~m}$ ahead, the energy exceeds the threshold, and the roof has obvious 

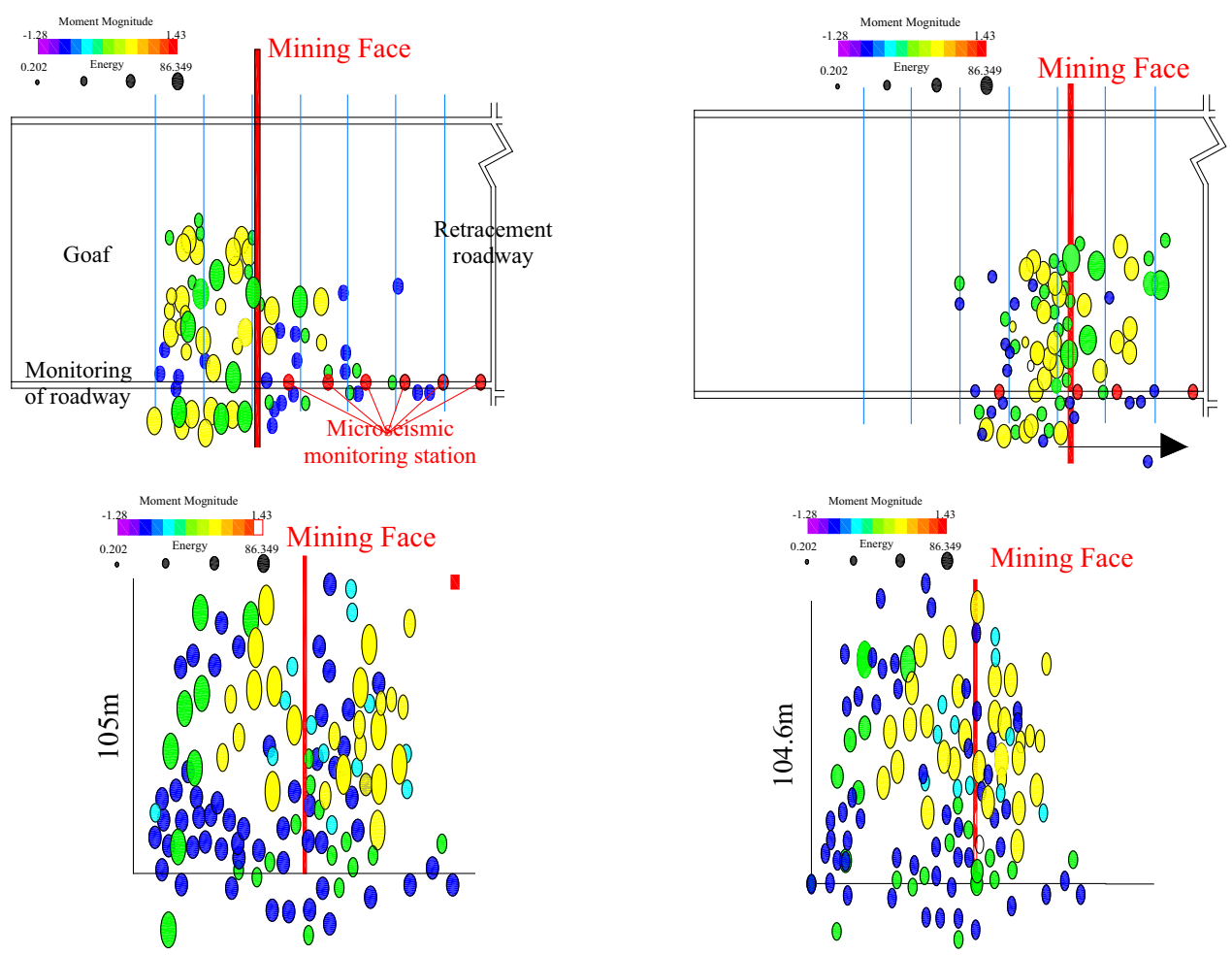

(a) Mining face advance $10 \mathrm{~m}$
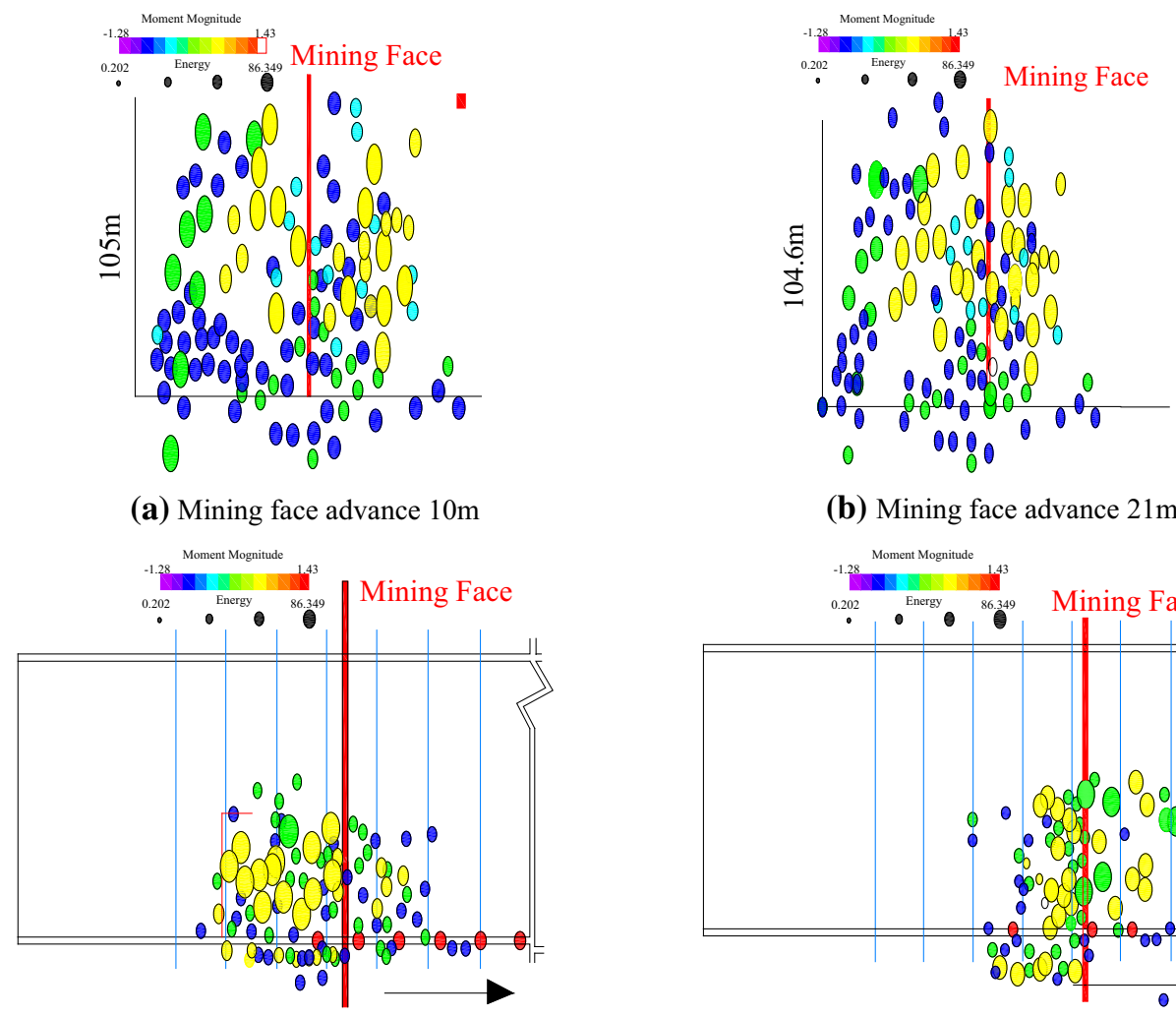

(b) Mining face advance $21 \mathrm{~m}$
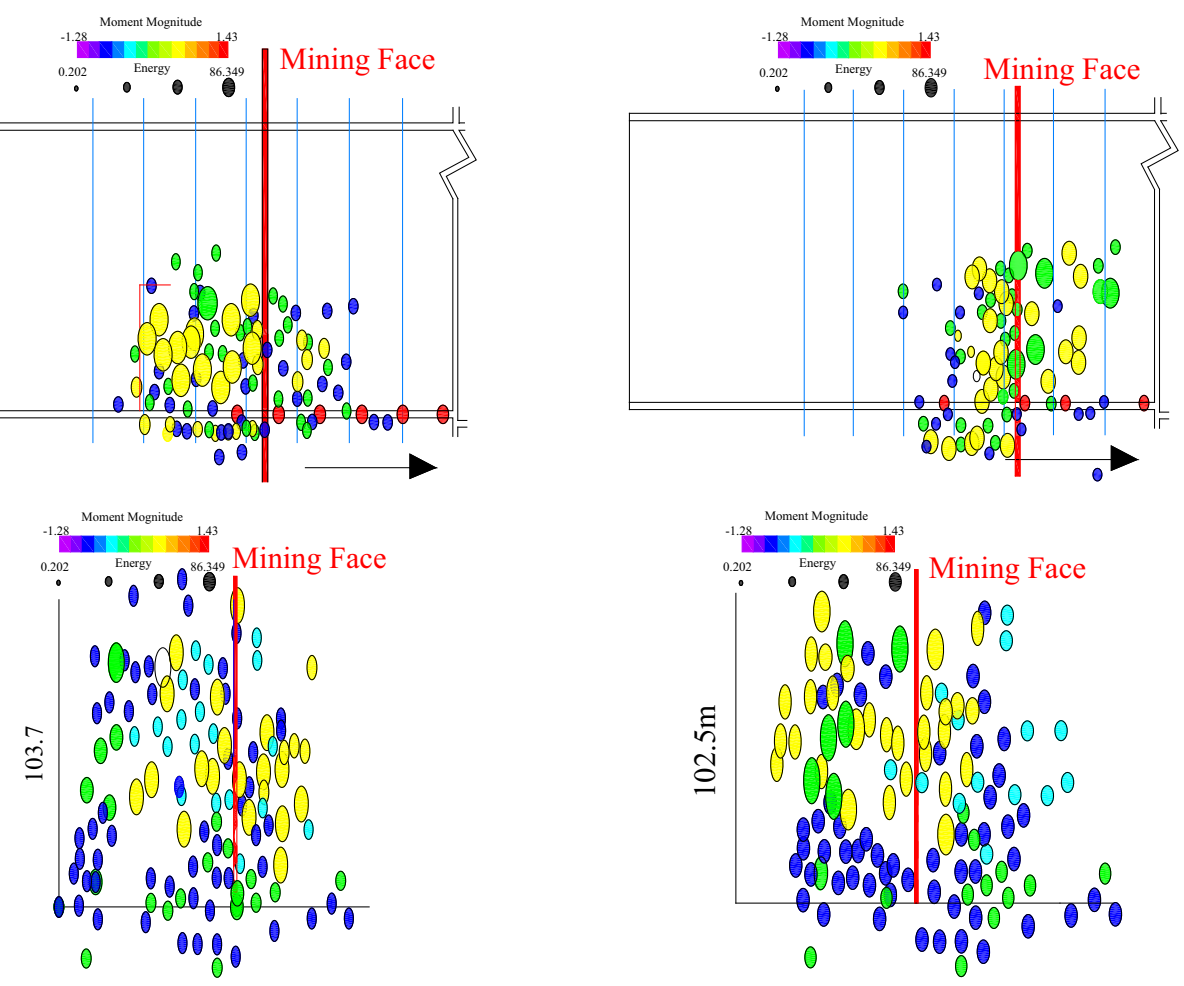

(c) Mining face advance $30 \mathrm{~m}$

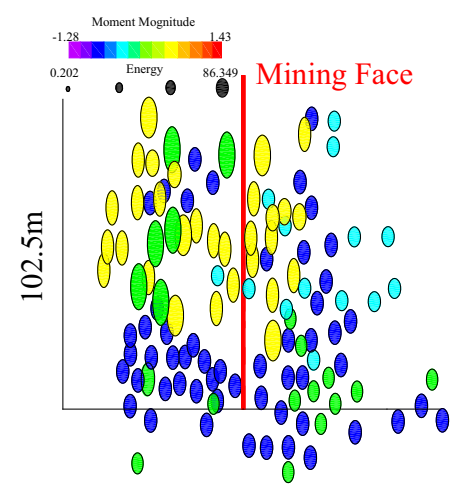

(d) Mining face advance $44 \mathrm{~m}$ 
4Fig. 7 Distribution characteristics of microseismic events at mining face

macroscopic cracks, which is the area where the roof is broken in advance. There is no obvious roof movement in this area, and the development of fissures is dominant.

\section{Roof Movement Area}

The density and energy of microseismic events within the range of $0-32 \mathrm{~m}$ behind the mining face have greatly increased, and the roof movement characteristics are obvious. From the position of $30 \mathrm{~m}$ behind the mining face, the density and intensity of

Table 4 Microseismic event distribution data

\begin{tabular}{|c|c|c|c|c|c|}
\hline $\begin{array}{l}\text { Mining face } \\
\text { position }\end{array}$ & $\begin{array}{l}\text { Number of } \\
\text { microquakes }\end{array}$ & $\begin{array}{l}\text { Vertical distribution } \\
\text { range }(\mathrm{m})\end{array}$ & $\begin{array}{l}\text { Leading distribution } \\
\text { range }(\mathrm{m})\end{array}$ & $\begin{array}{l}\text { Lag distribution } \\
\text { range }(\mathrm{m})\end{array}$ & $\begin{array}{l}\text { Influence area of coal } \\
\text { wall side }(\mathrm{m})\end{array}$ \\
\hline Advance $10 \mathrm{~m}$ & 174 & $25-80$ & $0-24$ & $0-45$ & 7 \\
\hline Advance $21 \mathrm{~m}$ & 247 & $21-85$ & $0-20$ & $0-40$ & 8 \\
\hline Advance $30 \mathrm{~m}$ & 247 & $19-79$ & $0-19$ & $0-32$ & 8 \\
\hline Advance $44 \mathrm{~m}$ & 247 & $19-84$ & $0-18.4$ & $0-34$ & 12 \\
\hline $\begin{array}{l}\text { Advance } 123 \\
\text { m }\end{array}$ & 177 & $22-80$ & $0-16.7$ & $0-43$ & 11 \\
\hline $\begin{array}{l}\text { Advance } 135 \\
\mathrm{~m}\end{array}$ & 185 & $19.7-85$ & $0-19.4$ & $0-41$ & 6 \\
\hline
\end{tabular}
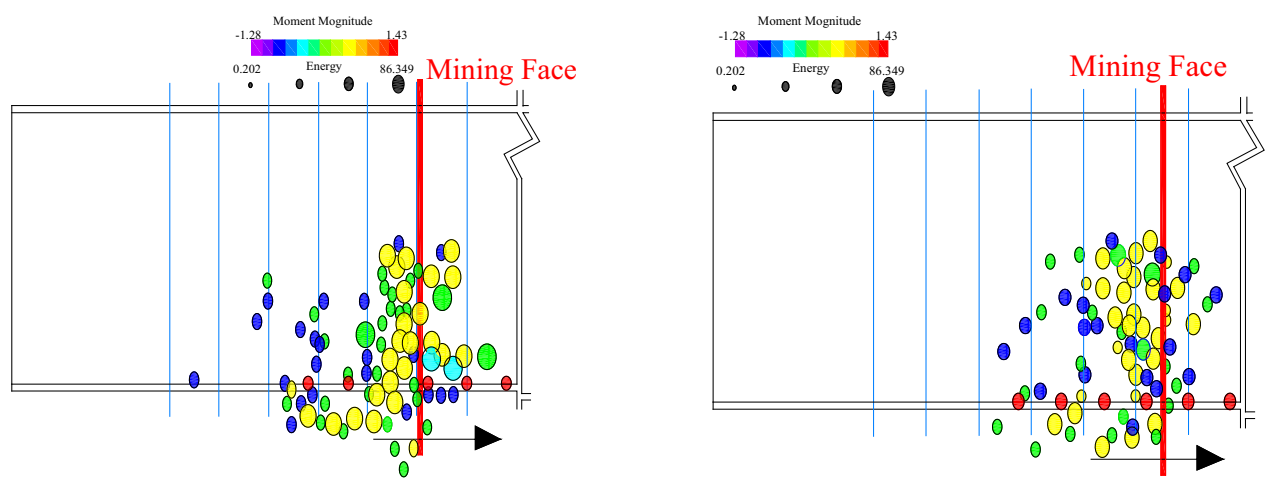

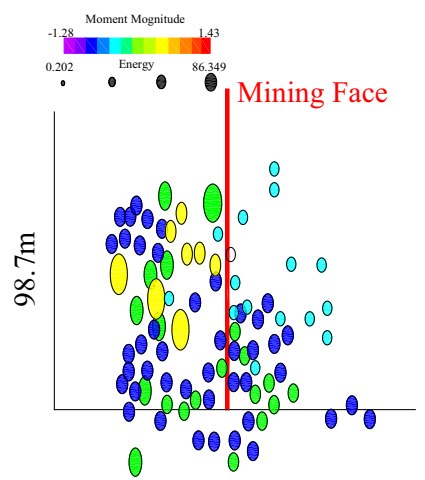

(e) Mining face advance $123 \mathrm{~m}$

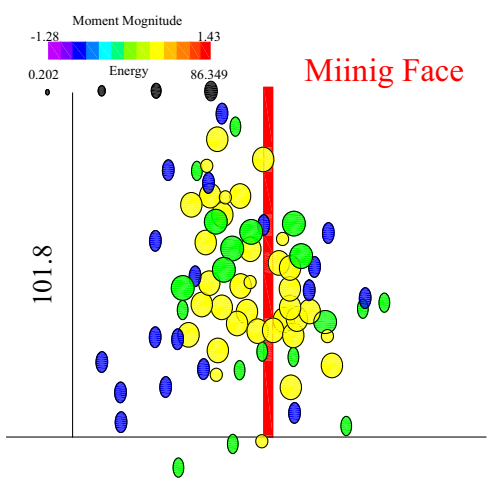

(f) Mining face advance $135 \mathrm{~m}$

Fig. 7 continued 


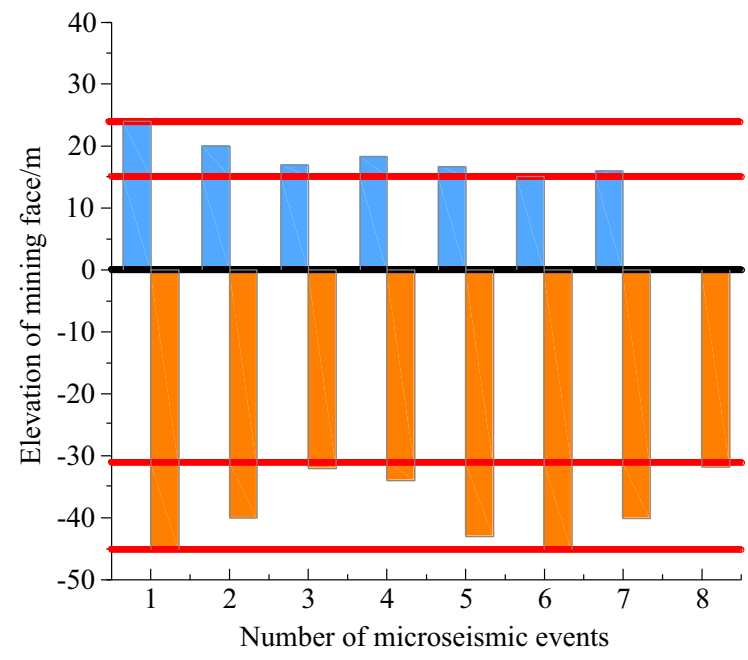

Fig. 8 The impact range

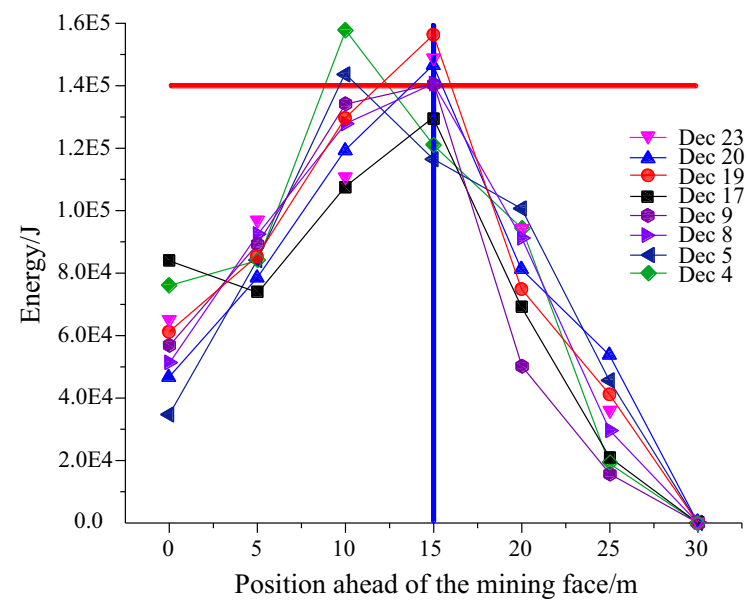

Fig. 9 Energy distribution curve

microseismic events have been significantly reduced, and the roof movement tends to be stable.

\section{Lateral Breaking Position}

This is an important parameter of the roof movement characteristics at the lateral breaking position of the roof when the roof is cut without coal pillars along the goaf. The monitoring results show that the microseismic events on the coal wall side of the entry have a distribution range of 6-12 m, of which the microseismic events at 6-8 $\mathrm{m}$ are linearly distributed, with high concentration and greater energy than the macro breaking energy standard. This position is the lateral breaking position of the entry roof.

\section{(3) Vertical Distribution Characteristics of Micro- seismic Events}

To take the vertical distribution characteristics of microseismic events from the mining face to $30 \mathrm{~m}$ as an example (Figures 10 and 11), the distribution of microseismic events has obvious regional characteristics and can be divided into fracture generation area, roof movement area and fracture development area.

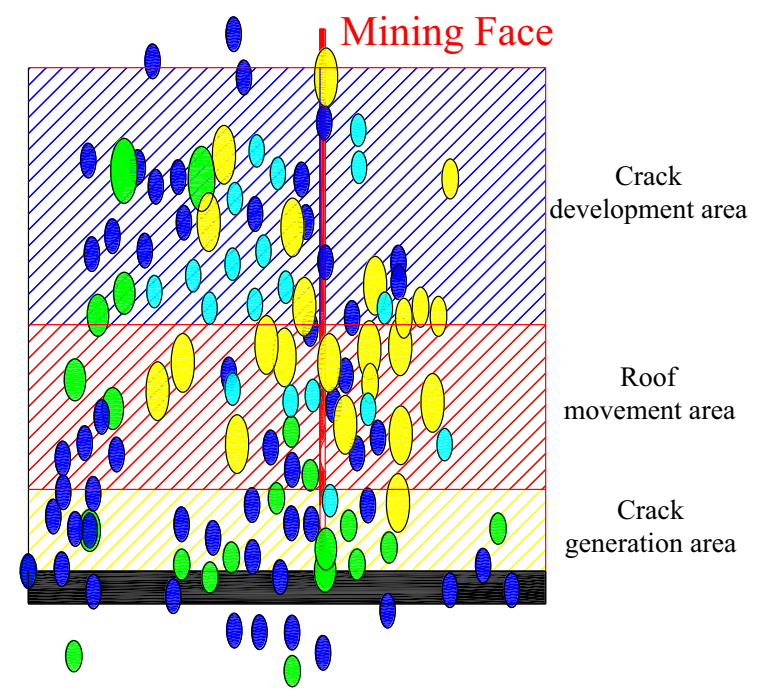

Fig. 10 Vertical distribution characteristics

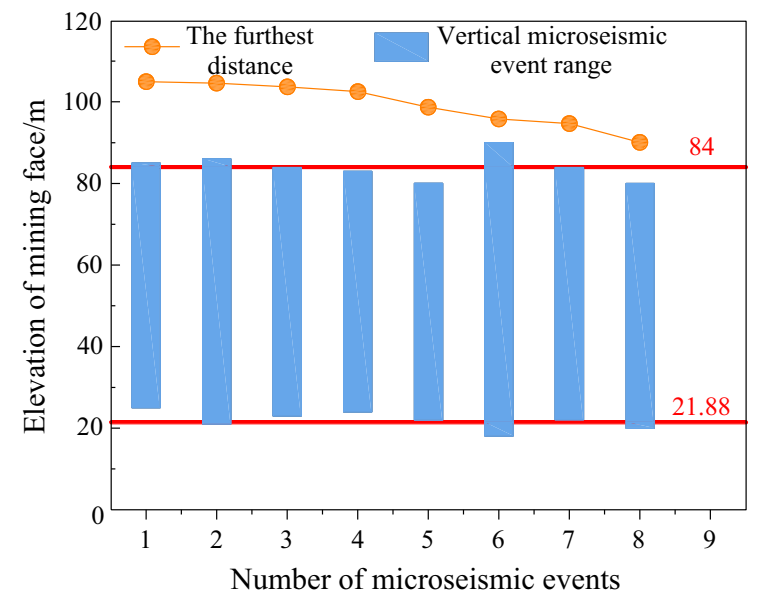

Fig. 11 Vertical concentration range 
1 Crack generation area

Within the range of $0-12 \mathrm{~m}$ above the roof of the entry, the density and energy of microseismic events are low, and there is no obvious macroscopic fracture, and the cracks are the main cause. This height is mainly the range of roof cutting height. The roof cutting effect cuts off the interconnection between the roofs. The roof of the entry remains relatively stable without significant breakage and movement. This is the main feature of the overburden failure of the roof with RCN$\mathrm{P}$ mining.

\section{Roof movement area}

The range of $21-45 \mathrm{~m}$ above the entry is the roof movement area. At this stage, the density and energy of microseismic events have greatly increased. By the criterion of the energy of microseismic events, macroscopic cracks develop. This range is mainly the main height range of the basic roof movement.

3 Crack development area

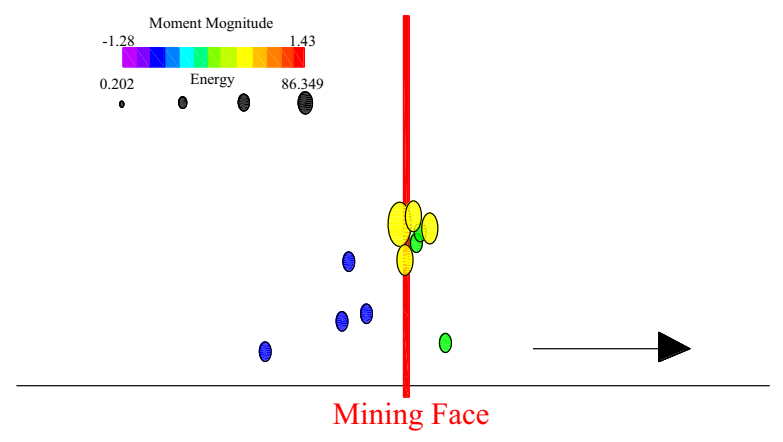

(a) Advance $0.6 \mathrm{~m}$

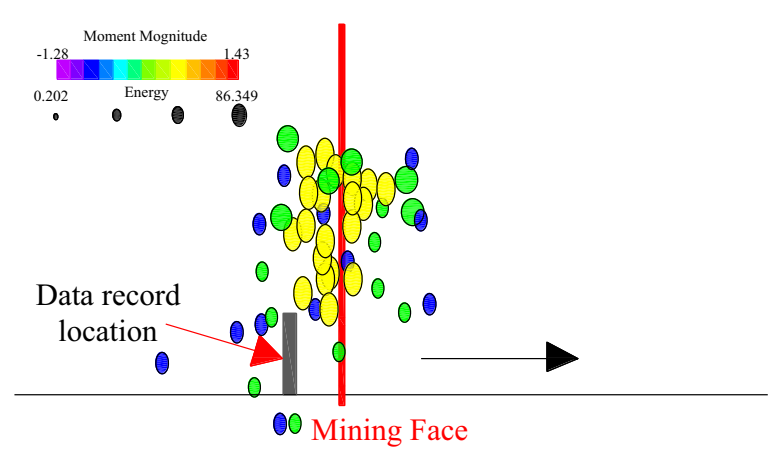

(c) Advance $20.3 \mathrm{~m}$

Fig. 12 Period distribution characteristics of microseismic events
The 45-84 $\mathrm{m}$ above the entry has a high concentration of microseismic events, but the energy is less than the macro-breaking energy standard. It is mainly based on the development of fractures. This height range is the height of the fracture zone of coal mining, so this area is a fracture development area.

The above analysis results show that, according to the spatial structure distribution characteristics of microseismic events, the entry roof can be horizontally divided into "two zones and one line", that is, the crack generation zone, the roof movement zone, and the lateral secondary breaking line. 10-15 m ahead of the mining face is the area where the leading cracks are generated. The breaking movement of the roof is concentrated in the range of $30 \mathrm{~m}$ behind the mining face. The roof of the entry is likely to be laterally broken 6-8 $\mathrm{m}$ inside the coal wall of the entry, and the roof above the entry is obviously broken. The lateral fracture of the thick coal seam is a typical feature of

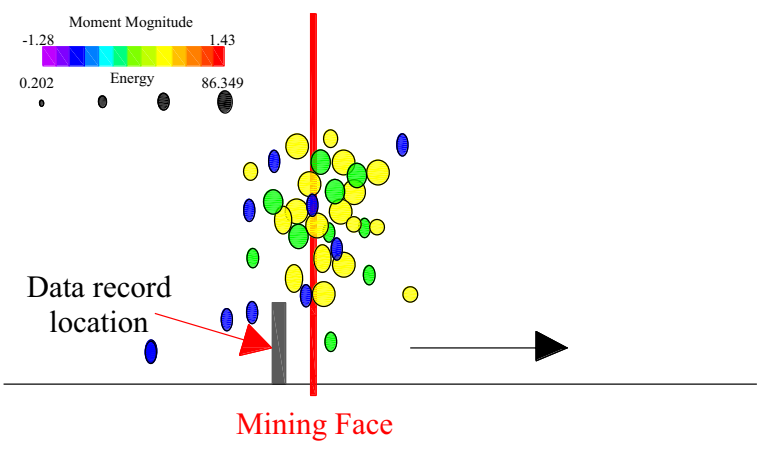

(b) Advance $9.4 \mathrm{~m}$

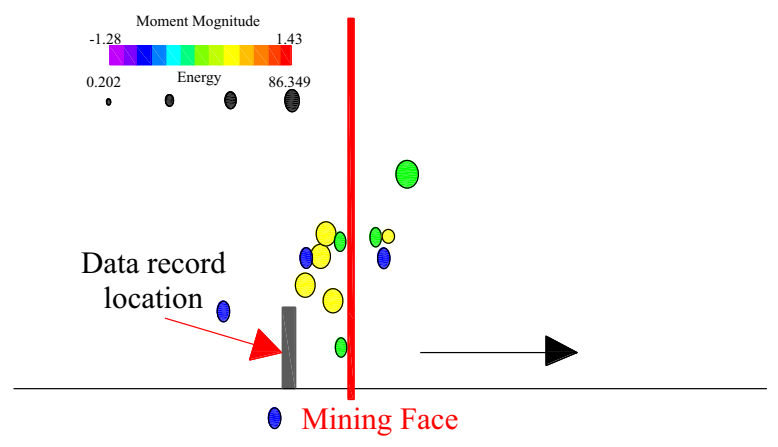

(d) Advance $20.91 \mathrm{~m}$ 
the horizontal fracture of the roof of the thick coal seam with RCN-P mining.

\subsection{Periodic Breaking Rule of Roof}

The regularity of microseismic distribution was strong when the mining face was advanced from 106.4 to $165.9 \mathrm{~m}$, as shown in Fig. 12.

During the mining process, the microseismic event of the entry roof changed periodically with an average period of 2 days. At the beginning, there were few microseismic events and low energy. As the exploitation continued, the number of microseismic events gradually increased and the energy was high. When the mining reached a certain distance, the number of microseismic events reached the peak, and the event energy was the highest. Subsequently, the microseismic events decreased sharply, and the high-energy microseismic event disappeared quickly. The mining process of the mining face repeated the abovementioned periodic process.

Through the microseismic monitoring of 3 complete cycles of pressure on the $2^{-2}$ coal $4.0 \mathrm{~m}$ large mining height with RCN-P mining of Ningtiaota colliery, the microseismic events showed periodic changes. According to the distribution characteristics of microseismic events, their cyclical development can be divided into the initial period, the middle period and the end of cyclical recovery. The monitoring data showed that when the mining face was in the initial

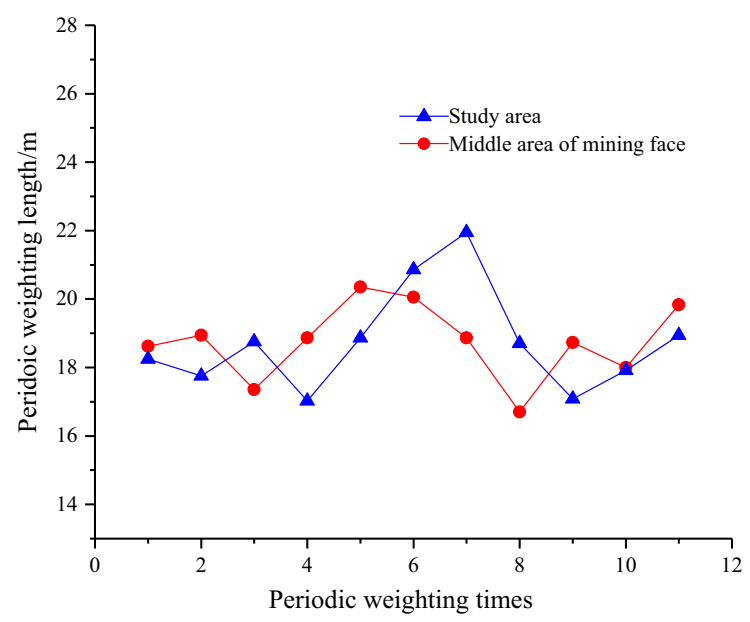

Fig. 13 Periodic weighting length of microseismic monitoring period of $0.6 \mathrm{~m}, 20.91 \mathrm{~m}$ and $40.43 \mathrm{~m}$, the system monitored 11, 10 and 8 microseismic events, respectively. When the mining face was at $9.4 \mathrm{~m}, 30.01 \mathrm{~m}$, and $50.01 \mathrm{~m}$ in the mid-cycle mining, the system monitored 74, 68, and 73 microseismic events, respectively. When the mining face was $20.3 \mathrm{~m}$, $39.81 \mathrm{~m}$, and $59.61 \mathrm{~m}$ at the end of the period, the system monitored 196, 185 and 179 microseismic events.

Based on the above content, the periodic development process of microseismic events can be summarized:

1 In the initial stage of the period weighting, the previous period of mining had just ended, the roof had undergone a process of breaking and pressure relieved. The development of microseismic events near the mining face was low and mild, and only a few microseismic events were distributed about $17 \mathrm{~m}$ ahead.

2 In the mid-period stage of the period weighting, when the mining face was mined to a position of $9.4 \mathrm{~m}$, there was a concentrated microseismic event $14 \mathrm{~m}$ ahead of the mining face. The microseismic event was mainly vertically distributed in the range between 21.56 and $70.23 \mathrm{~m}$. Under normal circumstances, this area was easy to form advanced macroscopic cracks. In the subsequent mining process, the frequency and intensity of microseismic events in this area had greatly increased, and vertically extended to a higher level, and the advanced macroscopic cracks had further intensified.

3 In the final stage of the period weighting, when the mining face was mined to $19.46 \mathrm{~m}$, the distribution range, intensity and frequency of microseismic events had reached the maximum, the macroscopic fractures developed to the greatest extent, and the basic roof reached the limit breaking state.

The results of the microseismic monitoring were drawn into the curve as shown in Fig. 13. The analysis showed that the average weighting length was the $18.74 \mathrm{~m}$ in the RCN-P mining area, and the value in the middle area of mining face was $18.76 \mathrm{~m}$.

In addition, through manual on-site monitoring, the periodic weighting length and intensity in the same period of time are counted. The data was shown in Table 5. 
Table 5 The statistics of periodic weighting length and strength

\begin{tabular}{|c|c|c|c|c|c|c|}
\hline \multirow{2}{*}{$\begin{array}{l}\text { Periodic weighting } \\
\text { times }\end{array}$} & \multicolumn{2}{|c|}{ Normal mining area } & \multicolumn{2}{|c|}{ Middle area of mining face } & \multicolumn{2}{|c|}{$\mathrm{RCN}-\mathrm{P}$ mining area } \\
\hline & $\begin{array}{l}\text { Strength } \\
\text { (MPa) }\end{array}$ & $\begin{array}{l}\text { Periodic length } \\
\text { (m) }\end{array}$ & $\begin{array}{l}\text { Strength } \\
\text { (MPa) }\end{array}$ & $\begin{array}{l}\text { Periodic length } \\
\text { (m) }\end{array}$ & $\begin{array}{l}\text { Strength } \\
\text { (MPa) }\end{array}$ & $\begin{array}{l}\text { Periodic length } \\
\text { (m) }\end{array}$ \\
\hline 1 & 29.24 & 15 & 38.6 & 17.3 & 39.2 & 15.9 \\
\hline 2 & 31.6 & 16.3 & 36.9 & 14.8 & 36.4 & 17.4 \\
\hline 3 & 28.6 & 15.8 & 38.6 & 18.9 & 37.4 & 21.3 \\
\hline 4 & 29.3 & 20.3 & 37.7 & 26 & 36.5 & 22.9 \\
\hline 5 & 32.6 & 24 & 37.4 & 25 & 37.5 & 23 \\
\hline 6 & 35.7 & 24.8 & 37.5 & 24.7 & 38.9 & 24.7 \\
\hline 7 & 39.8 & 19.6 & 38.2 & 23.1 & 34.9 & 15.7 \\
\hline 8 & 34.7 & 15.6 & 38.1 & 17 & 35.6 & 21.4 \\
\hline 9 & 35 & 17 & 39.5 & 18.2 & 36.8 & 16.9 \\
\hline 10 & 37.6 & & 37.9 & 18.9 & 37.6 & 15.6 \\
\hline Average value & 33.41 & 18.71 & 38.04 & 20.39 & 37.08 & 19.48 \\
\hline
\end{tabular}

As shown in the on-site statistics, the average period length of the study area was $18.16 \mathrm{~m}$. The average period length of microseismic monitoring was $18.74 \mathrm{~m}$. It can be seen that the periodic breakage of the roof was consistent with the periodic development characteristics of roof microseismic events, which fully demonstrated the accuracy of microseismic monitoring.

Compared with the normal area on the other side of the mining face, the RCN-P mining reduced the periodic weighting length by $10.2 \%$, and the pressure strength was increased by $11 \%$. The graph is shown in Fig. 13, data is shown in Table 5.

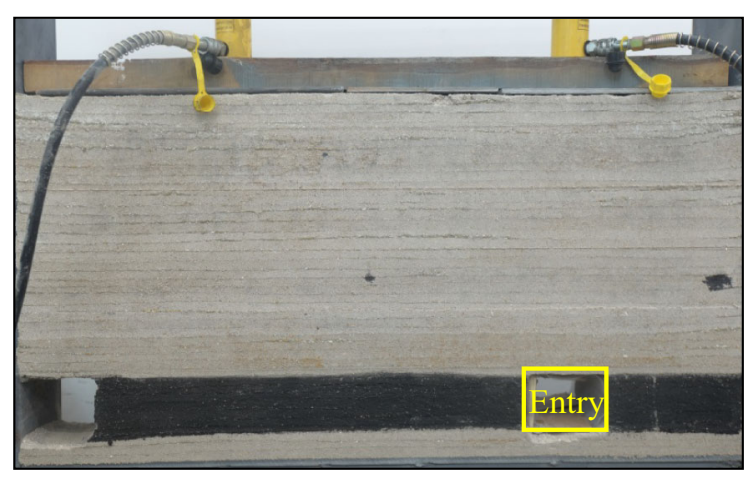

Fig. 14 Physical simulation panorama

\section{Physical Similarity Simulation Analysis of Roof Movement}

Gob-side entry retaining with RCN-P mining is affected by repeated mining on both sides of the mining face, and the roof structure of the entry is in a dynamic process of change. The evolution process of entry roof deformation and failure is mainly as follows: The mining disturbance at this mining face increases the stress of the surrounding rock of the entry $\rightarrow$ The roof slews down to the side of the goaf $\rightarrow$ The shallow surrounding rock is broken and the deep cracks increase $\rightarrow$ Basic roof breaks along the lateral side $\rightarrow$ The load of the supporting body increases and the deformation speed of the surrounding rock accelerates $\rightarrow$ The entry roof rotation subsidence further intensifies until it stabilizes $\rightarrow$ The entry continues and slowly deforms after the primary mining ends $\rightarrow$ The stress of the surrounding rock of the entry increases $\rightarrow$ The stress of the surrounding rock of the entry increases when the next mining face is mined $\rightarrow$ The entry is completely destroyed after mining.

\subsection{Simulation Experiment Design}

In the process of gob-side entry retaining with RCN-P mining, the mining conditions such as roof cutting parameters and mining height directly determine the breaking rule of the roof. In order to further reveal the 


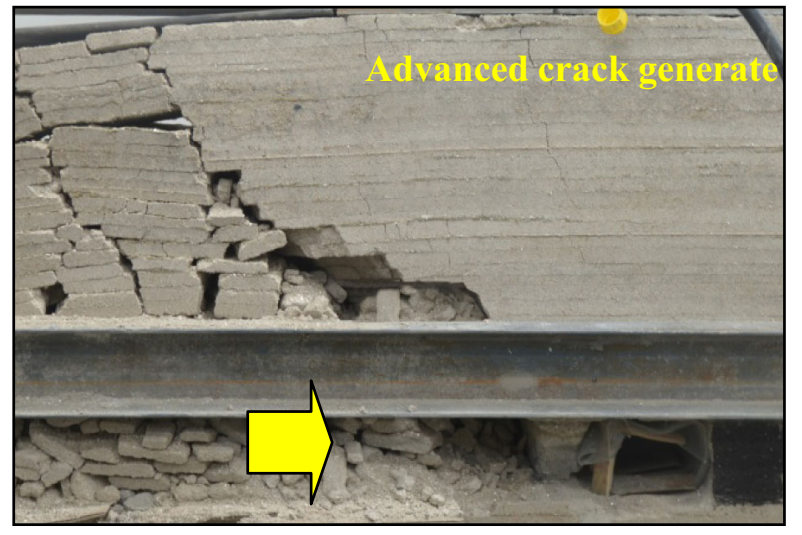

(a) Similarity simulation experiment results

Fig. 15 Triangular arch structure of Basic roof

rules of the roof movement of the entry without coal pillars, a physical similarity simulation experiments were carried out. The mining height was $4.3 \mathrm{~m}$, the roof cutting depth was $9 \mathrm{~m}$, and the roof cutting angle was $15^{\circ}$.

Based on the effect of roof cutting, the model design can maximize the observation of the failure movement of the roof cutting control layer (in the range of the roof cutting height) and the basic roof. Considering the effect of buried depth, load transfer and stress similarity ratio, the load effect on the upper part of the entry can be achieved by manual loading. The simulation experiment model had a width $\times$ height $\times$ thickness of $120 \mathrm{~cm} \times 80 \mathrm{~cm} \times$ $20 \mathrm{~cm}$, a geometric similarity ratio of 1:50 (satisfying

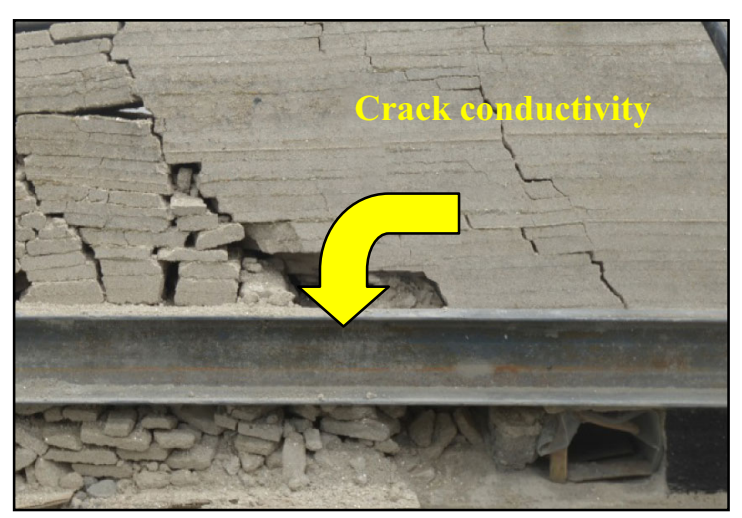

(a) Similarity simulation experiment results

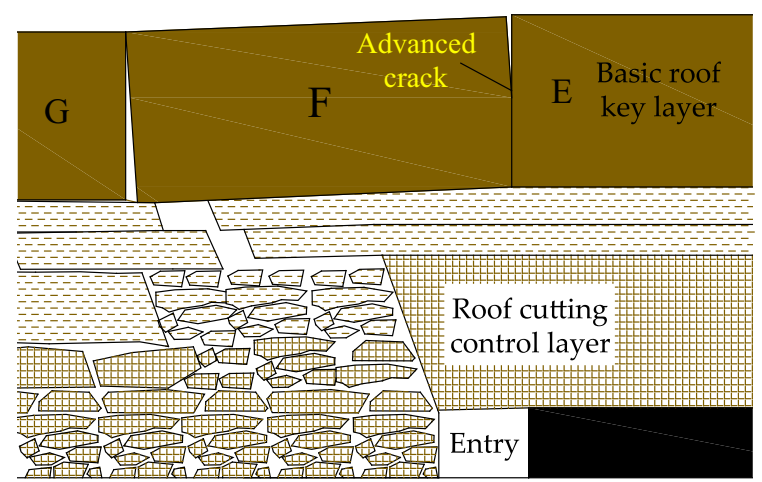

(b) Structural diagram full mining on the goaf side), a bulk density similarity ratio of $1: 1.5$, and a stress similarity ratio of 1:75. According to the stress similarity ratio, a uniform load of 0.2 MPa was applied to above the physical model, as shown in Fig. 14.

\subsection{Simulation Analysis of Roof Breaking Process}

\section{(1) Initial breaking stage of roof}

Before excavation, the roof on the side of the entry close to the mining face was cut. The initial load is uniform, and the original rock stress on the roof was simulated. In order to truly simulate the mining environment on site, the excavation was carried out

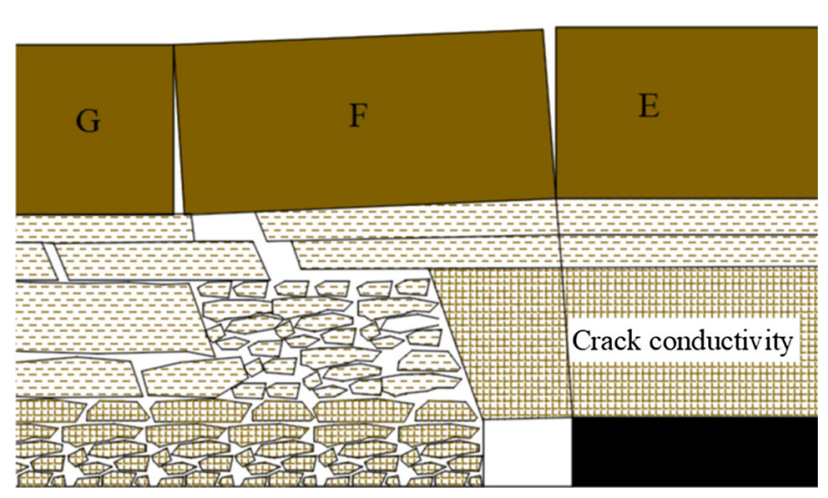

(b) Structural diagram

Fig. 16 The roof cutting control layer breaking 
quickly from left to right as shown in Figure 15. After the mining face excavation, the rock mass in the side goaf of the entry collapsed immediately, and the rock mass at the position of roof cutting was greatly broken. The roof cutting control layer formed a stable "short cantilever" structure. The key layer of the basic roof was broken in advance above the entry, turning and sinking toward the side of the goaf, and was hinged with the broken rock mass in the goaf to formed a hinged structure. The breaking angle of the basic roof key layer is $75^{\circ}$, and the limit breaking distance was $11.4 \mathrm{~m}$. The movement of the roof overlying strata at this stage was mainly due to the fracture of the basic roof key layer to form a lateral triangular arch structure.

\section{(2) Roof movement stage}

There was a continuous loading on the roof above the entry to simulate the force of the overlying surrounding rock. The rotation and subsidence of the basic roof key layer became more intense, so did the breaking and cracks on the entry roof. Under the force of the basic roof key layer, the roof cutting control layer broke along the coal wall of the entry, forming a conductive crack between the break line of the cutting roof control layer and the basic roof, and resulting in a $3^{\circ}$ rotation and cutting-off along the coal wall of the entry. The movement of the roof overlying rock at this stage was mainly due to the development of vertical fractures, which eventually penetrated the roof cutting control layer, forming conductive cracks on the roadside coal wall, as shown in Figure 16.

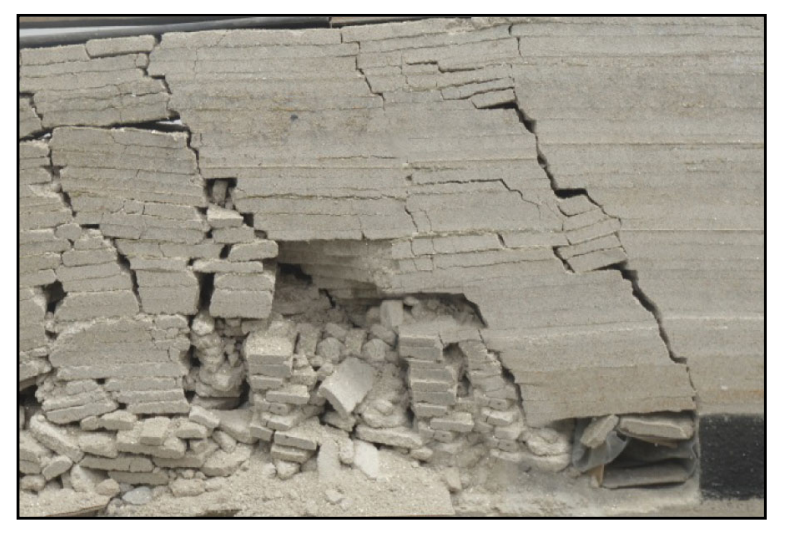

(a) Similarity simulation experiment results

\section{(3) Stabilization stage of the roof}

Stress was loaded to simulate the forces on the entry during the advance mining of the next working face, the entry roof cracks fully penetrated. The basic roof key block and the broken rock mass in the goaf formed a "masonry beam" structure and remain stable. The roof cutting control layer was cut off along the coal wall and formed a "short masonry beam" structure with the rock mass in the goaf. With the entry severely deformed and subjected to high roof pressure, the cutoff damage of the combined roof along the coal wall was the most dangerous form of RCN-P mining. With the entry severely deformed and subject to high roof pressure, the cut-off damage of the combined roof along the coal wall was the most dangerous form of RCN-P mining. In the field mining, the single-form pillars used in the entry were often crushed and the rotation characteristics of the roof were clearly seen, indicating the high stress in the roof and the reliability of the simulation phenomenon (Figure 17).

As indicated by the simulation experiment results, the key layer of the basic roof and the control layer of the cutting roof respectively constitute the "large " and "small" structures with RCN-P mining. The stability of the breaking structure of the basic roof key layer is the key to controlling the rock formation, and the breaking process from the "cantilever beam" to the "short masonry beam" of the roof cutting control layer was an important reason for the force in the entry.

The main purpose of control is mainly to prevent the roof from cut-off breaking during the RCN-P mining process. The control method is divided into

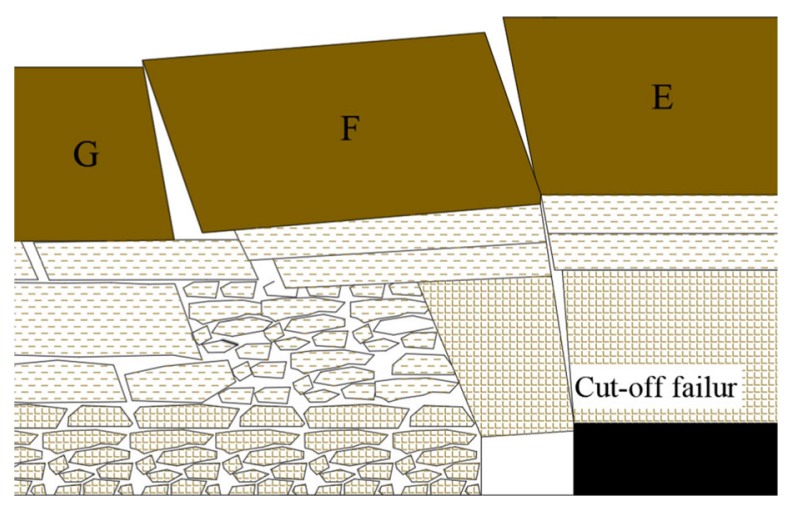

(b) Structural diagram

Fig. 17 Cut-off failure of roof 


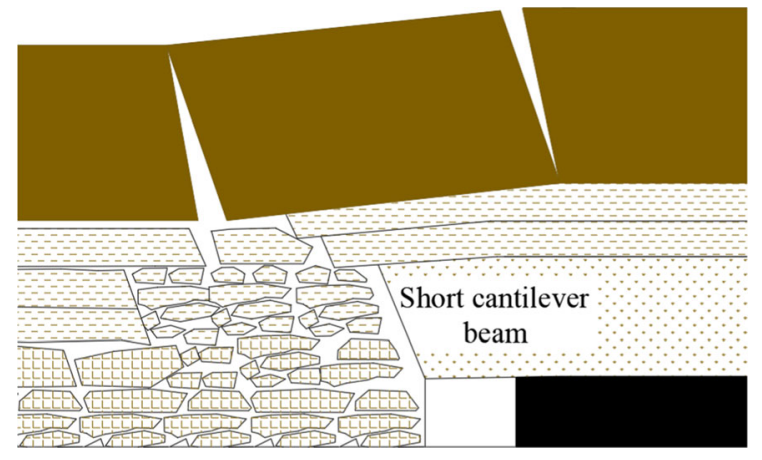

Fig. 18 "Short cantilever beam-masonry beam" structure

two parts: ensuring the stability of the roof cutting control layer and the basic roof fracture structure. Through this method, the roof cutting control layer does not break or breaks at the stable position inside the roadside coal wall, and a stable articulated structure can be formed after destruction. On the other hand, the basic roof fracture structure can support the load of the overlying rock layer, and reduce the stress transmission of the lower strata.

In addition, the stability of the roof structure of the thick coal seam with RCN-P mining was closely related to the cutting height. Shorter cutting roof height indicated less thickness of the control layer of cutting roof. As a result, the "small structure" had a weaker load support capacity. When the roof cutting height is large, the thickness of the top cutting control layer is increased, and the support capacity is enhanced, which effectively realizes the bearing of the overlying rock mass. At the same time, the

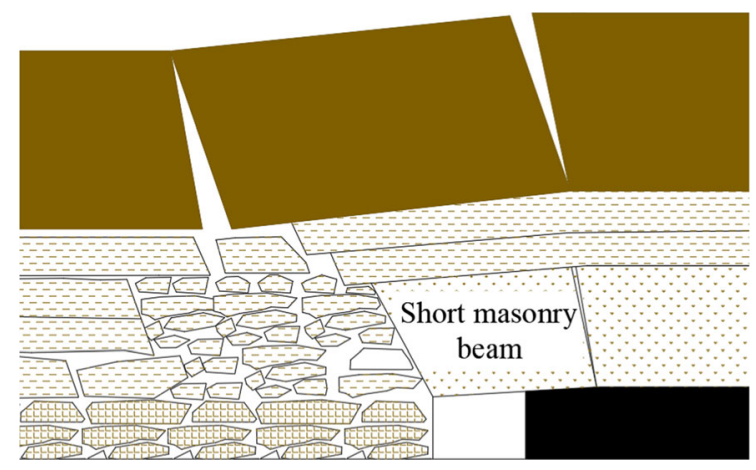

Fig. 19 "Short masonry beam—masonry beam" structure fragmentation and expansion effect of the cut rock mass are fully exerted, which is more conducive to maintaining the stability of the basic roof key layer.

\subsection{Roof Structure}

The roof structure of RCN-P mining was composed of the roof cutting control layer and the basic roof key layer. The results of physical similar simulation experiments showed that the breakage of the basic roof key layer would cause the structural instability of the short cantilever beam of the roof cutting control layer. When the stress of the cutting roof control layer was greater than its own strength, the roof is easy to break in the inner position of the coal wall of the entry. The main form of breaking was rotary breaking. One side of the broken key block was hinged with the stable roof of the inner coal wall, the other side was hinged to the rock mass cut in the goaf, forming a "short masonry beam " structure of the roof cutting control layer.

(1) "Short cantilever beam-masonry beam" structure

With the mining of the working face, the basic roof key layer was broken above the entry. The key blocks $\mathrm{E}, \mathrm{F}$ and $\mathrm{G}$ were hinged to each other after the roof broke. The roof cutting control layer within the range of cutting height did not break, hence forming a short cantilever structure. The structure of the basic roof key layer and the roof cutting control layer is masonry

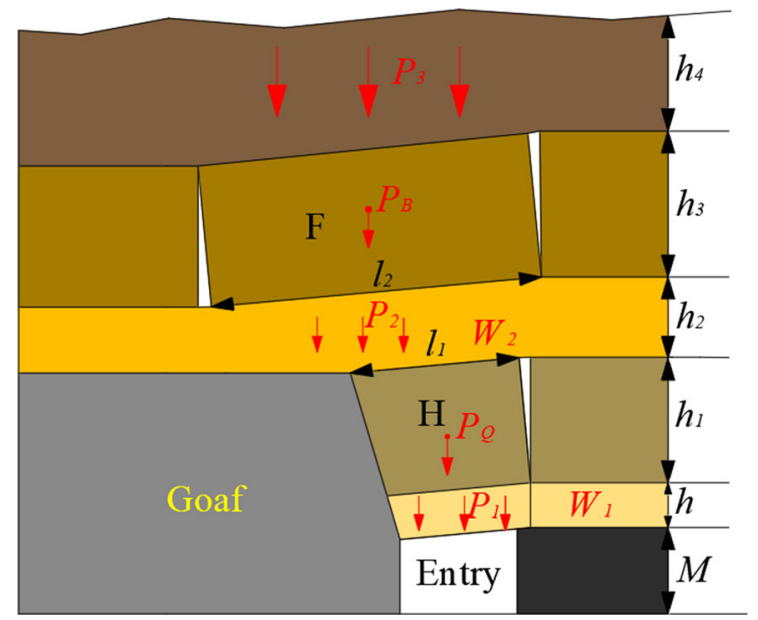

Fig. 20 Mechanical calculation model 


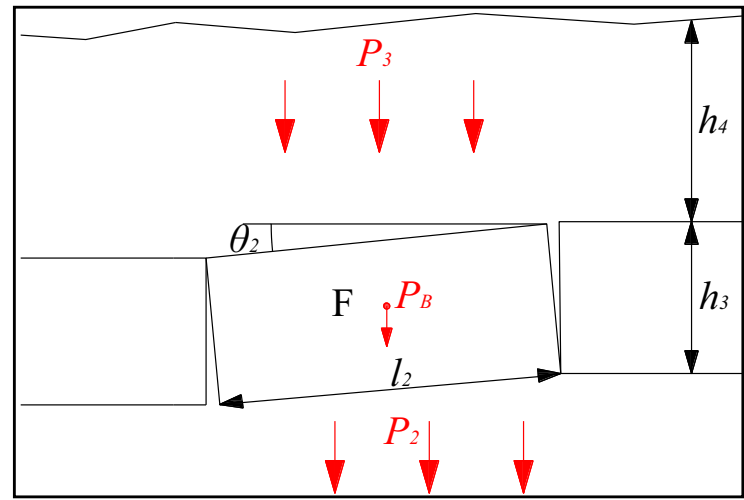

Fig. 21 Mechanical calculation model for basic roof key stratum

beam and short cantilever beam, respectively, which can be called "short cantilever beam-masonry beam " (Figure 18).

(2) "Short masonry beam-masonry beam"
structure

The "short cantilever beam-masonry beam " structural form was a temporary structural during the movement of the roof. With the continuous action of the surrounding rock stress, the roof broke along the weak surface of the crack under the action of the roof periodic breaking. After the basic roof key layer was broken, E, F and $\mathrm{G}$ were hinged to each other in the form of masonry beams. Under the action of the "large structure" of the basic roof, the roof cutting control layer broke the original short masonry structure and forms $\mathrm{H}$ rock block. The breaking location was inside the coal side of the entry. This basic roof key layer formed a masonry structure, and the cutting roof control layer formed a masonry structure. The structure was generally called "short masonry beammasonry beam", as shown in Figure 19.

"Short masonry-masonry beams" generally appeared in the mining process of RCN-P. The ultimate purpose of the support in the entry is to keep the structure stable, thereby improving the bearing capacity of the roof and maintaining the surrounding rock of the surrounding rock of the roadway.

\subsection{Mechanical Analysis}

According to the results of microseismic monitoring and physical similarity simulation experiments, a short masonry-masonry structure mechanical model was formed as shown in Fig. 20, the figure is established with RCN-P mining.

In Fig. 20, h4 is the thickness of the upper rock layer of the basic roof key layer, $h_{3}$ is the thickness of the basic roof key layer, $h_{2}$ is the thickness of the weak layer, $h_{1}$ is the thickness of the roof cutting control layer, $h$ is the thickness of the immediate roof, $M$ is for mining height, $l_{2}$ is the length of the key block F, $l_{2}$ is the length of the key block $\mathrm{H}$.

The roof stress of the entry include: $W_{1}$ is the immediate roof stress, $P_{1}$ is the stress of roof cutting control layer, $P_{\mathrm{Q}}$ is the weight of block $\mathrm{F}, W_{2}$ is the stress of the weak layer, $P_{2}$ is the stress of basic roof key layer, $P_{\mathrm{B}}$ is the weight of block, $P_{3}$ is the effective stress transmitted by upper rock layer of the basic roof key layer.

(1) Stress of basic roof key layer (as shown in Fig. 21)

$P_{3}=K_{G} l_{2} \sum h_{4} \gamma_{2}$

$K_{\mathrm{G}}$ is the load transfer coefficient (Huang 2002), $\gamma_{2}$ is the bulk density of the loading layer.

$K_{G}=\frac{l_{2}}{2 h_{3} \lambda_{3} \tan \varphi}$

$\lambda_{3}$ is the lateral stress coefficient of the overlying rock above the basic roof, $\varphi$ is the internal friction Angle.

$P_{B}=l_{2} \sum h_{3} \gamma_{1}$

The hinged structure formed after the key layer of the basic roof is broken exists in the form of masonry beam. By introducing the calculation formula of masonry beam (Huang et al. 2019), the formula can be introduced.

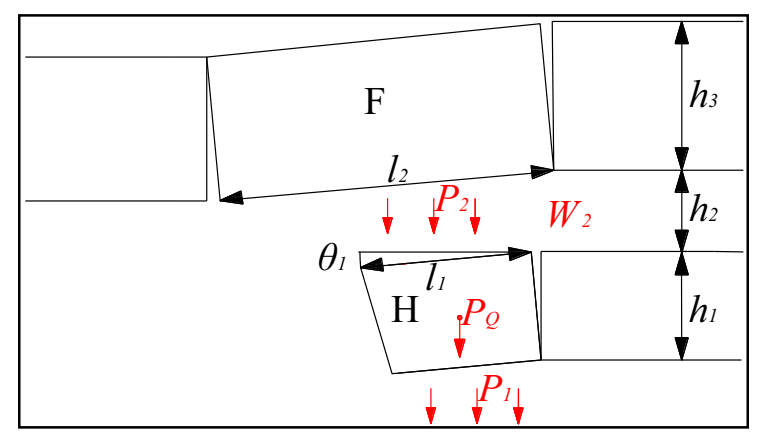

Fig. 22 Mechanical calculation model for control key stratum 
$P_{2}=\left(l_{2} \sum h_{3} \gamma_{1}+P_{3}\right)\left[\frac{4 i_{2}-3 \sin \theta_{2}}{2\left(2 i_{2}-\sin \theta_{2}\right)}-\frac{\tan \varphi_{2}}{i_{2}-\sin \theta_{2}+2 \sin \theta_{2}}\right]$

$\gamma_{1}$ is the bulk density of bedrock, $i_{2}$ is the ratio of length to thickness of block F, $\theta_{2}$ is the rotation angle of block F, $\varphi_{2}$ is the internal friction angle of bedrock.

(2) Stress of the weak layer

The force of the weak rock formation is the weight of the overlying rock between the roof cutting control layer and the basic roof key layer, and it acts directly on the roof cutting control layer in the form of a load.

$W_{2}=l_{1} \sum h_{2} \gamma_{2}$

(3) Stress of roof cutting control layer (as shown in Fig. 22)

The hinge structure formed after the roof cutting control layer is destroyed is a short masonry beam structure (Qian et al. 2018). The formula can be introduced.

$P_{Q}=l_{1} \sum h_{1} \gamma_{1}$

$P_{1}=\frac{1.7-\left(1.2+4.6 i_{1}\right) \tan \theta_{1}}{4-1.2 \tan \theta_{1}}\left(P_{2}+W_{2}+P_{Q}\right)$

According to the formula $(4,5,6)$ :

$P_{1}=\frac{1.7-\left(1.2+4.6 i_{1}\right) \tan \theta_{1}}{4-1.2 \tan \theta_{1}}\left(l_{1} \sum h_{1} \gamma_{1}+P_{2}+l_{1} \sum h_{2} \gamma_{2}\right)$

$i_{1}$ is the ratio of length to thickness of block $\mathrm{H}, \theta_{1}$ is the rotation angle of block $\mathrm{H}$.

(4) Stress of immediate roof

$W_{1}=l_{1} \sum h \gamma_{2}$

To sum up, it is determined that the minimum support resistance R to keep the roof stable by RCN-P mining is:

$R \geq l_{1} \sum h \gamma_{2}+\frac{1.7-\left(1.2+4.6 i_{1}\right) \tan \theta_{1}}{4-1.2 \tan \theta_{1}}\left[l_{1} \sum h_{1} \gamma_{1}+P_{2}+l_{1} \sum h_{2} \gamma_{2}\right]$

\section{Conclusions}

(1) As can be seen from the microseismic detection results with RCN-P mining in thick coal seam, the horizontal distribution of microseismic events is featured by "two zones and one line", namely, the horizontal direction is divided into crack generation area and roof movement area, which are located 0-25 m ahead of and 0-32 m behind the mining face, respectively. The microseismic events, $4-8 \mathrm{~m}$ within the coal wall side of the entry in the inclined direction, are linearly distributed, where lays the secondary lateral breaking line.

(2) The vertical distribution of roof microseismic events with RCN-P mining is basically featured by "three zones." The crack generation area and the roof movement area are located 0-12 $\mathrm{m}$ and 13-45 $\mathrm{m}$ above the entry, respectively, with the latter being the main area of the entry roof breaking movement and the crack development area being more than $50 \mathrm{~m}$ above the entry.

(3) Periodic characteristics of microseismic events are obvious. Few microseismic events are distributed in the leading position in the initial stage of the period weighting. A concentrated event of microseisms occurred in the leading position of the working face in the middle stage, forming a leading macroscopic crack, expanding continuously. The distribution range, intensity and frequency of microseismic events reach the maximum, and basic roof reaches the limit breaking state in the final stage. Compared with the normal mining, the RCN-P mining reduces the periodic weighting length by $10.2 \%$, and the pressure strength is increased by $11 \%$.

(4) As is shown from the actual measurement and simulation results, the rock formations controlling the roof movement with RCN-P mining include: the basic roof key layer located within the roof movement area and outside the cutting height range, and the roof cutting control layer located in the crack generation zone within the height of the roof cutting area, which has a bearing function. The thickness of roof cutting control layer is mainly affected by the cut parameters. Shorter cutting roof height indicates less thickness of the cutting roof control layer 
and weaker bearing capacity of the "small structure." The great height of roof cutting predicts the increasing thickness of the roof cutting control layer and the enhancing bearing capacity, which effectively realizes the bearing of the overlying rock mass.

(5) The breaking and rotation of the basic roof key layer formed the basic roof side triangular arch structure, with the basic broken roof being featured by "masonry beam" structure of the key block. It is easy to cut and break along the coal wall when the roof cutting control layer cannot bear the force of the overlying surrounding rock. The breaking position is the lateral breaking line of microseismic monitoring, forming a "short masonry" structure, forming a "short masonry beam-masonry beam" structure with the basic roof. Through mechanical analysis, the structure model is established, the mechanical analysis is conducted, and the calculation method to the roof-stablility minimum supporting resistance in the entry is obtained.

Acknowledgements We thank the National Natural Science Foundation of China for its support of this study. We thank the academic editors and anonymous reviewers for their kind suggestions and valuable comments.

Author's contribution Conceptualization, LZ; Experimental Design, MZ and QH; Validation, LZ and MZ; Theoretical Analysis, QH and MZ; Data Curation, KX; Supervision, YW; Writing-Original Draft Preparation, MZ; Writing-Review and Editing, LZ and WG Supervision, MZ; Project Administration, LZ; Funding Acquisition, LZ

Funding This research was funded by the National Natural Science Foundation of China, Grant Number No. 51674190.

\section{Declarations}

Conflict of interest The authors declare no conflict of interest.

Open Access This article is licensed under a Creative Commons Attribution 4.0 International License, which permits use, sharing, adaptation, distribution and reproduction in any medium or format, as long as you give appropriate credit to the original author(s) and the source, provide a link to the Creative Commons licence, and indicate if changes were made. The images or other third party material in this article are included in the article's Creative Commons licence, unless indicated otherwise in a credit line to the material. If material is not included in the article's Creative Commons licence and your intended use is not permitted by statutory regulation or exceeds the permitted use, you will need to obtain permission directly from the copyright holder. To view a copy of this licence, visit http://creativecommons.org/licenses/by/4.0/Lei.

\section{References}

Guo RP (2020) Influence of the interval length of hydraulic packer systems on thermally-induced pore pressure measurements in rock. Int J Rock Mech Min Sci 135:1-9

He MC, Zhang GF, Yu XP (2011) Research on the technique of no-pillar mining with gob-side entry formed by advanced roof caving in the protective seam in Baijiao coal mine. J Ming Saf Eng 21:511-516

He MC, Song ZQ, Wang A, Yang HH, Qi HG, Guo ZB (2017) Theory of longwall mining by using roof cutting shortwall team and 110 method: the third mining science and technology reform. Coal Sci Technol Mag 13:1-9

He MC, Gao YB, Yang J, Gong LW (2017) An innoavtive approach for gob-side entry retaining in thick coal seam longwall mining. Energies 10:1785-1807

$\mathrm{Hu}$ JZ, He MC, Ma ZM, Zhang YX (2019) Key parameters of roof cutting of gob-side entry retaining in a deep inclined thick coal seam with hard roof. Energies 12:934-953

Hua XZ, Zhang DL (2009) Research on supporting technology of gob-side entry retaining in the deep mining 2: 4-38

Huang QX (2002) Ground pressure behavior and definition of shallow seams. Chin J Rock Mech Eng 21:1174-1177

Huang QX, Zheng C (2016) Theory of self-stable ring in roadway support. Rock Soil Mech 37:1231-1236

Huang QX, Zhao MY, Zhang QF, Shao SC, Ma KS (2016) Mechanisms of outward dislocation sliding of roadway sides and its support in a thick coal seam with a soft mudstone interlayer. Rock Soil Mech 37:2353-2358

Huang QX, Zhao MY, Huang KJ (2019) Study of roof double key strata structure and support resistance of shallow coal seams group mining. J China Univ Min Technol 48:71-77

Ma K, Sun XY, Tang CA, Yuan FZ, Wang SJ, Chen T (2021) Floor water inrush analysis based on mechanical failure characters and microseismic monitoring. Tunn Undergr Space Technol 108:103698

Li S, Li JW, Fan CJ, Luo MK, Han YL (2015) Roof subsidence laws and control technology for gob-side entry retaining in fully-mechanized top-coal caving face. J China Coal Soc 40:1989-1994

Li LF, Li G, Gong WL, Wang J, Deng HL (2019) Energy evolution pattern and roof control strategy in non-pillar mining method of goaf-side entry retaining by roof cuttinga case study. Sustainability 11:7029-7048

Liu TC (1994) Application and development in maintaining roadways without chain pillars. Ground Pressure and Strata Control 4

Liu X, Hua XZ, Yang P, Huang ZG (2020) A study of the mechanical structure of the direct roof during the whole process of non-pillar gob-side entry retaining by roof cutting. Energy Explor 0:1-19

Luan HJ, Jiang YJ, Lin HL, Li GF (2018) Development of a new gob-side entry-retaining approach and its application. Sustainability 10:470-485 
Mahdevari S, Shahriar K, Sharifzadeh M, Tannant DD (2017) Stability prediction of gate roadways in longwall mining using artificial neural networks. Neural Comput Appl 28:3537-3555

Mikkelsen PE, Green GE (2003) Piezometers in fully grouted boreholes. In: Symposium on field measurements in geomechanics. oslo, norway: fmgm 2003; september:a.a. balkema

Zhang N, Han C, Kan J (2014) Theory and practice of surrounding rock control for pillarless gob-side entry retaining. J China Coal Soc 39(8):1635-1641

Qian MG (2015) On sustainable coal mining in China. J China Coal Soc 35:529-534

Qian MG, Xu JL, Wang JC (2018) Further on the sustainable mining of coal. J China Coal Soc 43:1-12

Song ZQ, Cui ZD, Xia HC (2010) The fundemental theoretial and engineering research on the green safe no coal pillar mining model by mainly using coal gangue backfill. J China Coal Soc 35:705-710

Wang JW, Wang SB, Yang J, Wang Q, Ma LL, He MC (2017) Roof failure mechanism of gob-side entry retaining by roof cutting and pressure releasing and its control technology. Coal Sci Technol 8:80-84

Wang SC, Dou LM, Wang ZY, Bai JZ, Chai YJ (2020) Mechanism of coal bursts induced by horizontal section mining of steeply inclined coal seams and application of microseismic multiparameter monitoring in early warning. $A d$ vances in civil engineering

Yang XJ, Wang EY, Ma XG, Zhang GF, Huang RF, Lou HP (2019) A case strdy on optimization and control techniques for entry stability in non-pillar longwall mining. Energies 12:291-308

Zhang N, Yuan L, Han CL, Xue JH, Kan JG (2012) Stability and deformation of surrounding rock in pillarless gob-side entry retaining. Saf Sci 50:593-599

Zhen EZ, Wang YJ, Yang J, He MC (2019) Comparison of the macroscopical stress field distribution characteristics between a novel non-pillar mining technique and two other current methods. Adv Mech Eng 5:1-15

Zhu Z, He MC, Wang Q, Gao YB, Wang YJ (2019) An innovative non-pillar mining method for gateroad formation automatically and its application in Ningtiaota coal mine. Journal China Univ Min Technol 48

Publisher's Note Springer Nature remains neutral with regard to jurisdictional claims in published maps and institutional affiliations. 